\title{
Clinical outcomes of locking polymeric clip for laparoscopic appendectomy in patients with appendicitis: a retrospective comparison with loop ligature
}

\author{
Seokwon Kim, Byong Ho Jeon, Sang Sik Cho, Ui Sup Shin, Sun Mi Moon \\ Department of Surgery, Korea Institute of Radiological and Medical Sciences, Seoul, Korea
}

Purpose: This study aimed to compare the clinical outcomes of laparoscopic appendectomy (LA) according to the method of appendiceal stump closure.

Methods: Patients who underwent LA for appendicitis between 2010 and 2020 were retrospectively reviewed. Patients were classified into locking polymeric clip (LPC) and loop ligature (LL) groups. Clinical outcomes were compared between the groups.

Results: LPC and LL were used in 188 (56.6\%) and 144 patients (43.4\%), respectively for appendiceal stump closure. No significant differences were observed in sex, age, comorbidities, and the severity of appendicitis between the groups. The median operative time was shorter in the LPC group than in the LL group ( 64.5 minutes vs. 71.5 minutes, $\mathrm{P}=0.027)$. The median hospital stay was longer in the LL group than in the LPC group (4 days vs. 3 days, $\mathrm{P}=0.020$ ). Postoperative incidences of intraabdominal abscess and ileus were higher in the LL group than in the LPC group $(4.2 \%$ vs. $1.1 \%, \mathrm{P}=0.082$ and $2.8 \%$ vs. $0 \%, P=0.035$; respectively). The readmission rate was higher in the LL group than that in the LPC group (6.3\% vs. $1.1 \%, \mathrm{P}=0.012$ ).

Conclusion: Using LPC for appendiceal stump closure during LA for appendicitis was associated with lower postoperative complication rate, shorter operative time, and shorter hospital stay compared to the use of LL. Operative time above 60 minutes and the use of LL were identified as independent risk factors for postoperative complications in LA. Therefore, LPC could be considered a more favorable closure method than LL during LA for appendicitis.

Keywords: Laparoscopic appendectomy; Polymeric clip; Appendicitis; Stump closure; Endoloop

\section{INTRODUCTION}

In many countries, laparoscopic appendectomy (LA) has become the standard surgical procedure for treating acute appendicitis [14]. Regardless of the presence of accompanying complications, LA is known to be associated with less pain, lower rates of postoperative morbidity, and shorter hospital stay than open surgery

Received: Jul 9, 2021 - Revised: Jul 26, 2021 - Accepted: Jul 27, 2021

Correspondence to: Sang Sik Cho, M.D.

Department of Surgery, Korea Institute of Radiological and Medical

Sciences, 75 Nowon-ro, Nowon-gu, Seoul 01812, Korea

Tel: +82-2-970-1251, Fax: +82-2-978-2005

E-mail: whtkdtlr@kirams.re.kr

ORCID: https://orcid.org/0000-0002-5358-106X

(c) 2022 The Korean Society of Coloproctology

This is an open-access article distributed under the terms of the Creative Commons Attribution NonCommercial License (https://creativecommons.org/licenses/by-nc/4.0) which permits unrestricted non-

commercial use, distribution, and reproduction in any medium, provided the original work is properly cited.
[5-9]. Appendiceal stump closure is a key procedure during LA. Inappropriate stump closure can cause appendiceal stump leakage, which can lead to serious postoperative complications. Several methods for appendiceal stump closure are widely used in LA. These include locking polymeric clip (LPC), loop ligature (LL), and endostapler. Among these, LPC and LL are the most commonly used methods for appendiceal stump closure due to their cost-effectiveness and ease of application. However, it is still unclear which method is better [10-12]. Therefore, this study aimed to investigate the safety and usefulness of LPC for appendiceal stump closure during LA and to compare these data with those of LL.

\section{METHODS}

\section{Ethical approval}

This study was approved by the Institutional Review Board of the 
Korea Cancer Center Hospital (No. KIRAMS 2021-02-002). The requirement for informed consent was waived by the Korea Cancer Center Hospital Institutional Review Board due to the retrospective nature of the study.

\section{Data collection}

Medical records of patients who underwent LA for acute appendicitis between January 2010 and December 2020 at the Korea Cancer Center Hospital (Seoul, Korea) were reviewed retrospectively. Patients with pathologically confirmed appendicitis who underwent LA using LPC or LL were included in the analysis. The exclusion criteria were (1) open conversion, (2) use of a stapler for stump closure, and (3) presence of appendiceal cancer or neoplasm associated with appendicitis. Finally, 188 and 144 patients who underwent LA with LPC and LL, respectively were included in the analysis. The median follow-up duration was 5 months (range, 0-119 months).

\section{Surgical procedure}

Altogether, 11 surgeons performed LA. Among these, 3 surgeons were non-gastrointestinal (GI) surgeons. The GI surgeons were experts who performed more than 50 cases of laparoscopic operations a year. The non-GI surgeons performed less than 3 cases of laparoscopic operations a year. The number and placement of laparoscopic ports, need for drain insertion during surgery, wound closure method, and appendiceal stump closure method were determined according to the surgeon's preference. Usually, 2 LPCs (X-large size) or 2 LLs were located on the appendiceal stump, and a 3rd LPC or LL was applied toward the specimen side of the appendix before division of the appendix. Additional suturing was not performed. Mesoappendiceal tissue dissection techniques were left up to the discretion of the surgeon. Monopolar electrocauterization was used in 13 cases of LA, and the remaining cases were performed with ultrasonic energy devices. The exposed appendiceal stump mucosa was electrocauterized. In most of the cases, trainees participated as scopists or assistants and occasionally as operators under the supervision of specialists.

\section{Outcomes}

The primary outcome measure was the rate of postoperative complications. The secondary outcome variables were operative time, length of hospital stay after surgery, and readmission within 30 days of surgery due to surgical complications.

\section{Statistical analysis}

The chi-square test or Fisher exact test was used to compare categorical variables and Mann-Whitney U-test was used for continuous data to calculate the associations between defined groups. To identify factors that affected postoperative complications after LA, logistic regression analysis was performed. For multivariate analysis, stepwise backward elimination was applied, and factors with a significance level of $<0.05$ or $<0.2$ in univariate analysis were se- lected for further multivariate analysis. All statistical analyses were 2 -sided and statistical significance was set at $\mathrm{P}<0.05$. IBM SPSS Statistics ver. 23.0 (IBM Corp., Armonk, NY, USA) was used for all statistical analyses.

\section{RESULTS}

\section{Patients}

The characteristics of the patients who underwent LA with LPC $(\mathrm{n}=188)$ or LL $(\mathrm{n}=144)$ are presented in Table 1. No significant differences were observed in sex, age, body mass index, comorbidities (diabetes mellitus, hypertension), previous history of abdominal surgery, American Society of Anesthesiologists grade, rate of complicated appendicitis, drain insertion during operation, and duration of perioperative antibiotic administration between the groups. However, the LPC group exhibited a shorter maximum diameter of the appendix ( $10 \mathrm{~mm}$ vs. $11 \mathrm{~mm}, \mathrm{P}=0.024$ ), greater proportion of non-GI surgeons $(20.7 \%$ vs. $11.8 \%, \mathrm{P}=$ $0.038)$, higher rate of single-port surgery $(36.2 \%$ vs. $20.8 \%, \mathrm{P}=$ 0.002 ), and shorter operative time (64.5 minutes vs. 71.5 minutes, $\mathrm{P}=0.027)$ than the LL group.

\section{Postoperative outcomes}

The clinical outcomes after LA with LPC or LL are presented in Table 2. The LPC group exhibited a higher rate of total complications $(20.8 \%$ vs. $10.6 \%, P=0.013)$ compared to the LL group. Among these, surgical wound-related complications were the most common in both the groups. Intraabdominal abscess was more frequently reported in the LL group than in the LPC group, but without a significant difference ( $20.0 \%$ vs. $10.0 \%, \mathrm{P}=0.082)$. The incidence of postoperative ileus after LA was higher in the LL group than in the LPC group ( $13.3 \%$ vs. $0 \%, \mathrm{P}=0.035)$. Postoperative hospital stay was significantly longer (4 days vs. 3 days, $\mathrm{P}=$ 0.020 ) and the rate of readmission due to complications was significantly higher $(30.0 \%$ vs. $10.0 \%, \mathrm{P}=0.012)$ in the LL group than in the LPC group. Reasons for readmission in the LL group were postoperative ileus ( 3 patients) and intraabdominal abscess (6 patients). In the LPC group, 1 patient each was readmitted after surgery due to enterocolitis and intraabdominal abscess. Only 1 patient in the LL group required reoperation due to mechanical bowel obstruction after LA.

\section{Risk factors for postoperative complications}

In a univariate analysis of risk factors for postoperative complications, only operative time above 60 minutes and the method of appendiceal stump ligation were significant factors. Multivariate analysis also confirmed a meaningful relationship between operative time above 60 minutes and the application of LPC, with postoperative complications (operative time above 60 minutes: hazard ratio [HR], 2.623; 95\% confidence interval [CI], 1.283-5.363; $\mathrm{P}=$ 0.009; application of LPC: HR, 0.453; 95\% CI, $0.243-0.843$; $\mathrm{P}=$ 0.012) (Table 3). 
Table 1. Characteristics of the enrolled patients

\begin{tabular}{|c|c|c|c|}
\hline Characteristic & $\begin{array}{l}\text { Locking } \\
\text { polymeric clip } \\
\text { group } \\
(n=188)\end{array}$ & $\begin{array}{l}\text { Loop ligature } \\
\text { group } \\
\qquad(n=144)\end{array}$ & P-value \\
\hline Sex & & & $>0.999$ \\
\hline Male & $99(52.7)$ & $76(52.8)$ & \\
\hline Female & 89 (47.3) & $68(47.2)$ & \\
\hline Age (yr) & $40.5(8-83)$ & $35.0(6-83)$ & 0.305 \\
\hline Body mass index $\left(\mathrm{kg} / \mathrm{m}^{2}\right)$ & $23.0(14.9-35.6)$ & $22.4(13.9-38.1)$ & 0.202 \\
\hline Diabetes mellitus & & & 0.704 \\
\hline Yes & $16(8.5)$ & $14(9.7)$ & \\
\hline No & $172(91.5)$ & $130(90.3)$ & \\
\hline Hypertension & & & 0.195 \\
\hline Yes & $29(15.4)$ & $15(10.4)$ & \\
\hline No & $159(84.6)$ & 129 (89.6) & \\
\hline \multicolumn{2}{|c|}{ Previous history of abdominal surgery } & & $>0.999$ \\
\hline Yes & $27(14.4)$ & $21(14.6)$ & \\
\hline No & $161(85.6)$ & $123(85.4)$ & \\
\hline ASA PS classification & & & 0.744 \\
\hline I & $52(27.7)$ & $44(30.6)$ & \\
\hline$\|$ & $125(66.5)$ & $90(62.5)$ & \\
\hline III & $11(5.9)$ & $10(6.9)$ & \\
\hline \multicolumn{4}{|l|}{ Complicated appendicitis } \\
\hline Perforated & $25(13.3)$ & $19(13.2)$ & $>0.999$ \\
\hline Periappendiceal abscess & $5(2.7)$ & $6(4.2)$ & 0.541 \\
\hline $\begin{array}{l}\text { Maximum diameter of } \\
\text { appendix (mm) }\end{array}$ & $10(5-19)$ & $11(5-28)$ & 0.024 \\
\hline $\begin{array}{l}\text { Drain insertion during } \\
\text { operation }\end{array}$ & & & 0.612 \\
\hline Yes & $21(11.2)$ & $19(13.2)$ & \\
\hline No & $167(88.8)$ & $125(86.8)$ & \\
\hline Operator & & & 0.038 \\
\hline Gastrointestinal surgeon & $149(79.3)$ & $127(88.2)$ & \\
\hline $\begin{array}{l}\text { Non-gastrointestinal } \\
\text { surgeon }\end{array}$ & $39(20.7)$ & $17(11.8)$ & \\
\hline No. of ports & & & 0.002 \\
\hline Single & $68(36.2)$ & $30(20.8)$ & \\
\hline Multiple & $120(63.8)$ & $114(79.2)$ & \\
\hline $\begin{array}{l}\text { Perioperative use of } \\
\text { antibiotics (day) }\end{array}$ & $3(1-20)$ & $4(1-18)$ & 0.133 \\
\hline Duration of operation (min) & $64.5(15-144)$ & $71.5(23-181)$ & 0.027 \\
\hline
\end{tabular}

Values are presented as number (\%) or median (range).

ASA, American Society of Anesthesiologists; PS, physical status.
Table 2. Postoperative outcomes

\begin{tabular}{lccr}
\hline Variable & $\begin{array}{c}\text { Locking } \\
\text { polymeric } \\
\text { clip group } \\
(\mathrm{n}=188)\end{array}$ & $\begin{array}{c}\text { Loop } \\
\text { ligature group } \\
(\mathrm{n}=144)\end{array}$ & P-value \\
\hline Total No. of complications & $20(10.6)$ & $30(20.8)$ & 0.013 \\
$\quad$ Enterocolitis & $2(1.1)$ & $2(1.4)$ & $>0.999$ \\
Wound complications & $16(8.5)$ & $17(11.8)$ & 0.357 \\
Intraabdominal abscess & $2(1.1)$ & $6(4.2)$ & 0.082 \\
Postoperative ileus & $0(0)$ & $4(2.8)$ & 0.035 \\
Pneumonia & $0(0)$ & $1(0.7)$ & 0.434 \\
Clavien-Dindo classification & $1(0.5)$ & $2(1.4)$ & 0.502 \\
I & $11(5.9)$ & $19(13.2)$ & \\
॥ & $8(4.3)$ & $9(6.3)$ & \\
III & $3(2-20)$ & $4(0-30)$ & 0.020 \\
Postoperative hospital stay (day) & $2(1.1)$ & $9(6.3)$ & 0.012 \\
Readmission within 30 days of & & $1(0.7)$ & 0.434 \\
surgery & & & \\
Reoperation within 30 days of & $0(0)$ & & \\
surgery & & & \\
\hline Values are presented as number (\%) & 0 median (range). & \\
\hline
\end{tabular}

\section{DISCUSSION}

In the present study, we observed that the use of LL during LA was associated with a higher rate of total complications than the use of LPC. Among these, intraabdominal abscess is believed to be directly related to the method of appendiceal stump closure. Soll et al. [13] reported that intraabdominal abscess was less frequent ( $1 \%$ vs. $4 \%, \mathrm{P}=0.012)$ in the LPC group and application of LPC during LA was associated with a lower risk of intraabdominal abscess in the multivariate analysis (odds ratio, 0.25 ; $95 \% \mathrm{CI}$, 0.09-0.69; $\mathrm{P}=0.008)$. We also confirmed that the rate of abscess was higher in the LL group, but the difference was not statistically significant. On the other hand, the rate of postoperative ileus was significantly higher in the LL group than in the LPC group, which might be due to the prolonged operative time, a known risk factor for postoperative ileus $[14,15]$. These complications were the probable reasons for higher readmission rates in the LL group than in the LPC group.

Compared to the average operative times of LA with LPC (47.7 minutes; range, 31.1-66 minutes) or LL (54.8 minutes; range, 4766 minutes) reported in other studies [11], our results showed relatively longer operative times. The possible reasons for this finding are as follows. (1) Trainees participate in surgery for education, which is reported to be associated with a longer operative time [16-18]. (2) Our institution is a cancer-specific hospital that performs fewer than 30 cases of LA annually. (3) Non-GI surgeons who did not frequently perform laparoscopic surgery par- 
Table 3. Logistic regression analysis for the risk factors of postoperative complications after laparoscopic appendectomy

\begin{tabular}{|c|c|c|c|c|}
\hline \multirow{2}{*}{ Variable } & \multicolumn{2}{|c|}{ Univariate analysis } & \multicolumn{2}{|c|}{ Multivariate analysis } \\
\hline & $\mathrm{HR}(95 \% \mathrm{Cl})$ & P-value & $\mathrm{HR}(95 \% \mathrm{Cl})$ & P-value \\
\hline Age of $>60 \mathrm{yr}$ & $2.418(0.832-7.030)$ & 0.105 & $2.021(0.681-5.997)$ & 0.205 \\
\hline Female sex & $1.063(0.581-1.943)$ & 0.843 & & \\
\hline Diabetes mellitus & $1.142(0.416-3.139)$ & 0.797 & & \\
\hline Hypertension & $1.078(0.451-2.574)$ & 0.866 & & \\
\hline Complicated appendicitis & $1.755(0.850-3.627)$ & 0.129 & $1.467(0.674-3.190)$ & 0.334 \\
\hline Gastrointestinal surgeon & $0.911(0.415-2.001)$ & 0.817 & & \\
\hline Previous history of abdominal surgery & $0.957(0.403-2.272)$ & 0.920 & & \\
\hline Drain insertion during surgery & $1.777(0.789-4.004)$ & 0.165 & $1.078(0.350-3.319)$ & 0.895 \\
\hline Maximum diameter of appendix >10 mm & $0.805(0.440-1.471)$ & 0.481 & & \\
\hline Multiport surgery & $2.101(0.979-4.510)$ & 0.057 & $1.794(0.821-3.922)$ & 0.143 \\
\hline Operative time of $>60$ min & $2.626(1.292-5.339)$ & 0.008 & $2.623(1.283-5.363)$ & 0.009 \\
\hline Locking polymeric clip & $0.452(0.245-0.836)$ & 0.011 & $0.453(0.243-0.843)$ & 0.012 \\
\hline
\end{tabular}

$\mathrm{HR}$, hazard ratio; $\mathrm{Cl}$, confidence interval.

ticipated in this study. Similarly, the rate of total complications was relatively high compared to that in other studies [11] possibly due to the higher rate of complicated appendicitis compared to the average rates reported in other studies [19].

There has been a change in the rate of use of LPC and LL for 10 years. The use of LPC increased from $51.0 \%$ in the first half to $63.0 \%$ in the second half, while the use of LL decreased from $49.0 \%$ in the first half to $37.0 \%$ in the second half. Since we have never established a consensus on methods of LA, the increase in the use of LPC is thought to have simply increased with the operator's preference (considering the benefits of ease of use, cost-effectiveness, etc.). The rate of complications in both groups was shown to decrease in the second half of the decade, compared to the first half. This is thought to be the result of improvement in perioperative management. However, the difference in complications between the 2 groups was still significant and there was no change in operating time in both groups, throughout the entire period. Therefore, it appears that the presence of a learning curve due to increased experience was not a substantial influence on these factors.

Reportedly, application of LPC during LA has several advantages over LL. LPC is cheaper than LA [20-22]. Moreover, its application is easier due to lower technical requirements compared to $\mathrm{LL}$, which might contribute to shorter operative times $[13,23$, 24]. The results of the present study are consistent with these findings. Due to the aforementioned advantages, application of LPC in LA was preferred by non-GI surgeons who had less experience in laparoscopic surgery. Moreover, LPC was used more frequently than LL in single-port LA, which is associated with higher technical difficulty.

However, LPC has certain limitations. The maximum internal length of LPC is approximately $13 \mathrm{~mm}$. Thus, it can only be ap- plied if the diameter of the appendix is less than $12 \mathrm{~mm}$ [25]. In contrast, LL can be placed regardless of the diameter of the appendix. However, it is challenging for inexperienced surgeons to apply adequate tightening strength to the closed endoloops, as the pressure on the stump during closure depends on the tightening force used by the surgeon to lock the thread in place. Therefore, the knot of the endoloop has a potentially higher risk of slipping due to insufficient tightening. In contrast, transection or necrosis of the appendiceal stump might result if the knot is too tight. Another limitation of LPC is that it is difficult to remove compared to LL when it is misapplied. Therefore, if additional suturing is expected after stamp ligation, it is better to use LL rather than LPC. This is because additional suturing is often technically difficult when LPC remains in the stump of the appendix. Lastly, careful application of LPC is needed as crushing damage can occur if there is a content such as appendicolith in the location where LPC is applied, or if tissue inflammation is severe.

Delibegović and Mehmedović [25] reported that the diameter of the appendix was significantly longer in gangrenous or perforated appendicitis than in phlegmonous appendicitis. However, the results did not indicate whether it was associated with complications. In the present study, information regarding the diameter of the appendix in which the LPC or LL was located could not be obtained from the pathological reports, but it was confirmed that a higher maximum diameter of the appendix ( $>10 \mathrm{~mm}$ ) was associated with perforated appendicitis when compared with uncomplicated appendicitis ( $19.4 \%$ vs. $7.2 \%, \mathrm{P}=0.002)$. However, in the multivariate analysis, a maximum appendix diameter of $>10$ $\mathrm{mm}$ was not associated with postoperative complications. Therefore, the maximum diameter of the appendix may affect the decision regarding the stump closure method, but it is not considered a risk factor for postoperative complications. 
This study has limitations inherent to its retrospective design. However, although this was a single-institution study, surgeons from a variety of branches participated in the surgery. Moreover, the study has strengths such as analysis using detailed variables that can affect postoperative complications.

In conclusion, the use of LPC during LA is expected to result in lower complication rates, lower readmission rates, and shorter operative times than the use of LL. Therefore, LPC might be considered a safer and more efficient closure method than LL during LA for appendicitis.

\section{CONFLICT OF INTEREST}

No potential conflict of interest relevant to this article was reported.

\section{FUNDING}

None.

\section{REFERENCES}

1. Kleif J, Thygesen LC, Gögenur I. Moving from an era of open appendectomy to an era of laparoscopic appendectomy: a nationwide cohort study of adult patients undergoing surgery for appendicitis. Scand J Surg 2021;110:512-9.

2. Fujishiro J, Watanabe E, Hirahara N, Terui K, Tomita H, Ishimaru $\mathrm{T}$, et al. Laparoscopic versus open appendectomy for acute appendicitis in children: a nationwide retrospective study on postoperative outcomes. J Gastrointest Surg 2021;25:1036-44.

3. Gosemann JH, Lange A, Zeidler J, Blaser J, Dingemann C, Ure $\mathrm{BM}$, et al. Appendectomy in the pediatric population: a German nationwide cohort analysis. Langenbecks Arch Surg 2016;401: 651-9.

4. Masoomi H, Nguyen NT, Dolich MO, Mills S, Carmichael JC, Stamos MJ. Laparoscopic appendectomy trends and outcomes in the United States: data from the Nationwide Inpatient Sample (NIS), 2004-2011. Am Surg 2014;80:1074-7.

5. Yu MC, Feng YJ, Wang W, Fan W, Cheng HT, Xu J. Is laparoscopic appendectomy feasible for complicated appendicitis? A systematic review and meta-analysis. Int J Surg 2017;40:187-97.

6. Quah GS, Eslick GD, Cox MR. Laparoscopic appendicectomy is superior to open surgery for complicated appendicitis. Surg Endosc 2019;33:2072-82.

7. Del Pino C, Muñoz R, Rada G. Laparoscopic versus open appendectomy for complicated appendicitis. Medwave 2018;18:e7370.

8. Talha A, El-Haddad H, Ghazal AE, Shehata G. Laparoscopic versus open appendectomy for perforated appendicitis in adults: randomized clinical trial. Surg Endosc 2020;34:907-14.

9. Jaschinski T, Mosch CG, Eikermann M, Neugebauer EA, Sauerland S. Laparoscopic versus open surgery for suspected appendicitis. Cochrane Database Syst Rev 2018;11:CD001546.
10. Mannu GS, Sudul MK, Bettencourt-Silva JH, Cumber E, Li F, Clark AB, et al. Closure methods of the appendix stump for complications during laparoscopic appendectomy. Cochrane Database Syst Rev 2017;11:CD006437.

11. Makaram N, Knight SR, Ibrahim A, Patil P, Wilson MSJ. Closure of the appendiceal stump in laparoscopic appendectomy: A systematic review of the literature. Ann Med Surg (Lond) 2020;57: 228-35.

12. Lasek A, Wysocki M, Mavrikis J, Myśliwiec P, Bobowicz M, Dowgiałło-Wnukiewicz N, et al. Comparison of stump closure techniques during laparoscopic appendectomies for complicated appendicitis: results from Pol-LA (Polish laparoscopic appendectomy) multicenter large cohort study. Acta Chir Belg 2020;120:11623.

13. Soll C, Wyss P, Gelpke H, Raptis DA, Breitenstein S. Appendiceal stump closure using polymeric clips reduces intra-abdominal abscesses. Langenbecks Arch Surg 2016;401:661-6.

14. Artinyan A, Nunoo-Mensah JW, Balasubramaniam S, Gauderman J, Essani R, Gonzalez-Ruiz C, et al. Prolonged postoperative ileus-definition, risk factors, and predictors after surgery. World J Surg 2008;32:1495-500.

15. Story SK, Chamberlain RS. A comprehensive review of evidencebased strategies to prevent and treat postoperative ileus. Dig Surg 2009;26:265-75.

16. Mack J, Turner C, Carter D, Hallagan L, Whiting J, Falank C, et al. The effect of resident participation on appendectomy operative times. J Surg Educ 2020;77:e196-200.

17. Kim CW, Jeon SY, Paik B, Bong JW, Kim SH, Lee SH. Resident learning curve for laparoscopic appendectomy according to seniority. Ann Coloproctol 2020;36:163-71.

18. Lee W, Park SJ, Park MS, Lee KY. Impact of resident-performed laparoscopic appendectomy on patient outcomes and safety. J Laparoendosc Adv Surg Tech A 2018;28:41-6.

19. Sartelli M, Baiocchi GL, Di Saverio S, Ferrara F, Labricciosa FM, Ansaloni L, et al. Prospective Observational Study on acute Appendicitis Worldwide (POSAW). World J Emerg Surg 2018;13:19.

20. Lucchi A, Berti P, Grassia M, Siani LM, Gabbianelli C, Garulli G. Laparoscopic appendectomy: Hem-o-lok versus Endoloop in stump closure. Updates Surg 2017;69:61-5.

21. Wilson M, Maniam P, Ibrahim A, Makaram N, Knight SR, Patil P. Polymeric clips are a quicker and cheaper alternative to endoscopic ligatures for securing the appendiceal stump during laparoscopic appendicectomy. Ann R Coll Surg Engl 2018;100:454-8.

22. Kim S, Weireter L. Cost effectiveness of different methods of appendiceal stump closure during laparoscopic appendectomy. Am Surg 2018;84:1329-32.

23. Shaikh FM, Bajwa R, McDonnell CO. Management of appendiceal stump in laparoscopic appendectomy: clips or ligature. A systematic review and meta-analysis. J Laparoendosc Adv Surg Tech A 2015;25:21-7.

24. Delibegović $\mathrm{S}$. The use of a single Hem-o-lok clip in securing the base of the appendix during laparoscopic appendectomy. J Lapa- 
roendosc Adv Surg Tech A 2012;22:85-7.

25. Delibegović S, Mehmedović Z. The influence of the appendiceal base diameter on appendix stump closure in laparoscopic appendectomy. World J Surg 2016;40:2342-7. 